MAKSIMUM: Media Akuntansi Universitas Muhammadiyah Semarang, Vol.10(1) 2020, 41-46

https://jurnal.unimus.ac.id/index.php/MAX

Registered with the Indonesian Institute of Sciences with p-ISSN: 20872836 and e-ISSN: 2580-9482

\title{
Pengaruh Rasio Keuangan Terhadap Tindak Kecurangan Pelaporan Keuangan
}

\author{
Ika Listyawati \\ Fakultas Ekonomi, Universitas AKI, Indonesia
}

\begin{abstract}
Info Article
History Article:

Submitted: 5 Februari 2020

Revised: 20 Februari

2020

Accepted: 10 Maret 2020

Keywords:

fraud in financial

reporting, financial

leverage, liquidity,

profitability, and capital

turnover

Abstract

This study considers the effect of financial ratios on fraud in financial reporting. While the financial ratios issued are financial leverage, liquidity, profitability, and capital turnover. Research has been conducted using quantitative methods with secondary data. Secondary data comes from a list of cases in the Financial Reporting. This research uses purposive sampling method. The total sample obtained was 32 companies. This company classification consists of 32 companies that do financial reporting and 32 companies that do not commit financial reporting by collecting which companies produce the same industry and year of observation. This study uses logistic regression statistical tools while the dependent variable is a dummy (non-metric) variable, while the independent variable is a mixture of metric and non-metric variables. The results show that financial leverage, liquidity and capital turnover affect financial reporting fraud, while profitability has no effect.
\end{abstract}

JEL classifications:

H83, M34

How to Cite: Ika, L. (2020). Pengaruh Rasio Keuangan Terhadap Tindak Kecurangan Pelaporan Keuangan. MAKSIMUM, Vol.10(1), 41-46

\begin{tabular}{l}
\hline correspondence Address: Jl. Imam Bonjol No.15 - 17, Dadapsari, Kec. Semarang Utara, Kota \\
Semarang, Jawa Tengah 50173 \\
Institutional address: Universitas AKI Semarang \\
E-mail: ikalistyawati@gmail.com
\end{tabular}




\section{PENDAHULUAN}

Laporan keuangan merupakan ringkasan dari suatu proses pencatatan dan ringkasan dari transaksi keuangan yang terjadi selama periode tertentu. Laporan keuangan dibuat oleh manajemen dengan tujuan untuk memper-tanggungjawabkan tugas-tugas yang dibebankan (Baridwan, 2004). Dengan demikian laporan keuangan memiliki karakteristik kualitatif agar informasi dalam laporan keuangan berguna bagi pemakai. Karakteristik kualitatif tersebut antara lain primer dan sekunder. Kualitatif primer terdiri dari relevance dan reability, sedang-kan kualitatif sekunder terdiri dari comparability dan consistensi. Informasi yang disajikan dalam laporan keuangan harus relevan (relevance) agar kebutuhan pemakai (user) dalam proses pengambilan keputusan dapat terpenuhi serta harus memiliki keandalan (reliability), yaitu informasi harus bebas dari pengertian yang menyesatkan, kesalahan material, dan dapat diandalkan pemakainya sebagai penyajian yang seharusnya disajikan atau yang secara wajar dapat disajikan (Baridwan, 2004).

Pelaporan keuangan yang mengandung unsur kecurangan dapat merugikan kreditur dan investor. Dampaknya kreditur dan investor akan kehilangan sejumlah saham yang diinvestasikan, penurunan harga saham di pasar modal dan bahkan mengakibatkan kebangkrutan. Ke-curangan penyajian laporan keuangan yang dilakukan oleh manajer juga akan memberikan dampak yang kurang baik terhadap kepercayaan investor, partisipan pasar modal lainnya dan publik tentang kualitas dan kejujuran pelaporan keuangan (Rezae dalam Respati, 2011).

Merujuk pada penelitian yang dilakukan oleh Spathis (2002) menjelaskan bahwa skandal akuntansi telah berkembang secara luas, seperti halnya di Amerika Serikat. Kecurangan akuntansi yang menimpa Enron menimbulkan kerugian yang sangat besar di hampir seluruh industri. Dampak dari kecurangan tersebut sangat besar dan telah merugikan banyak pihak. Skandal akuntansi tersebut diperkirakan menimbulkan kerugian bagi Enron sebesar US\$50 miliar, ditambah lagi kerugian investor sebesar US\$32 miliar dan ribuan pegawai Enron harus kehilangan dana pensiun mereka sekitar US\$1 miliar.

\section{METHOD}

Metode penelitian mengguna-kan empat variabel keuangan sebegai prediksi kecurangan laporan keuangan, sampel yang digunakan 32 perusahaan yang melakukan kecurangan dan tidak melakukan kecurangan laporan keuangan. Disini menggunakan regresi logistik, yang mana variabel dependennya adalah variabel dummy. Persamaan yang dibentuk dengan menggunakan regresi logistik adalah sebagai berikut:

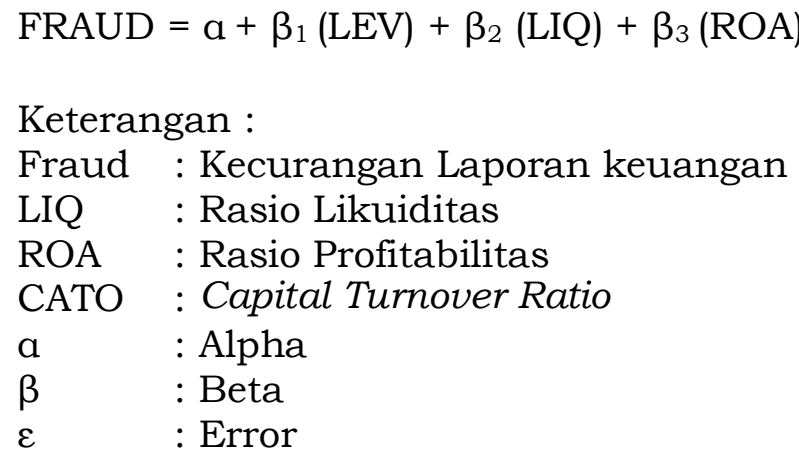

\section{HASIL DAN PEMBAHASAN Menilai Model Fit}

Untuk menguji bahwa data empiris cocok atau sesuai dengan model (tidak ada perbedaan antara model dengan data sehingga model dapat dikatakan fit) salah satunya dengan menggunakan nilai Hosmer and Lemeshow's Goodness of Fit Test. 
Tabel 1. GoF

\begin{tabular}{cccc}
\hline Step & Chi-square & df & Sig. \\
\hline 1 & 6.201 & 8 & .625 \\
\hline
\end{tabular}

Sumber: Data diolah

\section{Hosmer and Lemeshow's Goodness of Fit Test}

Hosmer and Lemeshow Test besarnya nilai statistik Hosmer and Lemeshow's goodness of Fit Test sebesar 6,201 dengan probabilitas signifikan 0,625 yang nilainya jauh diatas 0,05. Dengan demikian dapat ditarik kesimpulan bahwa model dapat diterima karena cocok dengan data observasinya, sehingga mampu memprediksi nilai observasinya.

\section{Cox and Snell's Square dan Negelkerke $R$ Square}

Cox and Snell's Square merupakan ukuran yang mencoba meniru ukuran $\mathrm{R}^{2}$ pada multiple regression yang didasarkan pada teknik estimasi likelihood dengan nilai maksimum kurang dari 1 (satu) sehingga sulit diinterpretasikan. Negelkerke $R$ Square merupakan modifikasi dari koefisien Cox and Snell untuk memastikan bahwa nilainya bervariasi dari 0 (nol) sampai 1 (satu).

Tabel 2. Uji Cox and Snell's R2

\begin{tabular}{cccc}
\hline Step & $\begin{array}{c}\mathbf{- 2} \text { Log } \\
\text { likelihood }\end{array}$ & $\begin{array}{c}\text { Cox \& Snell R } \\
\text { Square }\end{array}$ & $\begin{array}{c}\text { Nagelkerke R } \\
\text { Square }\end{array}$ \\
\hline 1 & $25.941_{\mathrm{a}}$ & .571 & .761 \\
\hline
\end{tabular}

Sumber: Data diolah

Nilai dari Cox and Snell's $R$ Square sebesar 0,571 dan nilai Nagelkerke $R$ Square sebesar 0,761 yang memiliki arti bahwa variabilitas variabel dependen yang dapat dijelaskan oleh variabilitas variabel independen sebesar $76,1 \%$, sedang-kan sisanya $23,9 \%$ dijelaskan oleh variable lain diluar model.

Statistik deskriptif memberi-kan gambaran atau deskripsi suatu data yang dilihat dari nilai rata-rata (mean), standar deviasi, maksimum dan minimum. Pada tabel 4.10 dibawah ini akan ditunjukkan statistik deskriptif untuk variabel dependen yaitu kecurangan pelaporan keuangan (FRAUD). Selanjutnya statistik deskriptif variabel independen financial leverage (LEV), likuiditas (LIQ), profitabilitas (ROA), dan capital turnover (CATO). Dalam pengujian hipotesis ini menggunakan alat statistik regresi logistik.

Tabel 3 hasil regresi logistik

\begin{tabular}{lcccc}
\hline \multicolumn{1}{c}{ Variabel } & B & S.E. & Wald & Sig \\
\hline Leverage & 17,464 & 7,09 & 6,054 & $0,014^{*}$ \\
Likuiditas & 0,976 & 0,41 & 5,657 & $0,017^{*}$ \\
Roa & $-26,91$ & 15,86 & 2,877 & 0,090 \\
Cato & $-4,035$ & 1,718 & 5,518 & $0,019^{*}$ \\
\hline
\end{tabular}

Sumber: Data diolah 


\section{Diskusi dan Pembahasan}

\section{Pengaruh Financial leverage (LEV) terhadap Kecurangan Pelaporan Keuangan}

Pernyataan hipotesis pertama menyatakan bahwa financial leverage perusahaan berpengaruh positif terhadap kecurangan pelaporan keuangan. Berdasarkan hasil uji regresi logistik dapat ditarik kesimpulan bahwa hipotesis pertama diterima karena signifikan dan dari hasil analisis statistik deskriptif menunjukkan bahwa nilai rata-rata untuk perusahaan yang melakukan kecurangan sebesar 0,63 sedangkan untuk perusahaan yang tidak melakukan kecurangan sebesar 0,42.

Hasil penelitian ini mendukung penelitian Persons (1995) yang memberikan hasil bahwa financial leverage berpengaruh positif terhadap kecenderungan kecurangan akuntansi. Hasil penelitian ini juga konsisten dengan penelitian Spathis (2002) dan Skousen, et al (2008) yang menunjukkan hasil bahwa nilai financial leverage yang dihasilkan perusahaan signifikan mempengaruhi kemungkinan tindak kecurangan pelaporan keuangan.

\section{Pengaruh Likudititas (LIQ) terhadap Kecurangan Pelapor-an Keuangan}

Pernyataan hipotesis kedua menyatakan bahwa likuiditas ber-pengaruh negatif terhadap kecurang-an pelaporan keuangan, hipotesis tidak diterima tetapi signifikan. Berdasarkan analisis data deskriptif yang dilakukan untuk memperoleh nilai rata-rata pada perusahaan yang melakukan curang dan perusahaan yang tidak melakukan curang sebesar 6,07 dan 1,85.

Hasil penelitian ini mendukung penelitian Kreutzfeldt dan Wallance (1986) yang didalam penelitiannya menyatakan bahwa masalah likuiditas dalam perusahaan memberikan pengaruh yang signifikan terhadap kesalahan dalam pelaporan keuangan dibandingkan dengan perusahaan dalam kondisi tidak mengalami masalah likuiditas. Kondisi semacam itu dapat terjadi jika perusahaan tersebut merupakan perusahaan besar dengan tingkat kepastian arus cash ratio dan quick ratio-nya tinggi serta dalam setiap melakukan transaksi perusahaan didukung dengan dana yang besar serta pembagian deviden yang kontinyu dan meningkat dapat memungkinkan kecenderungan pe-laporan keuangan dalam perusahaan dapat diminimalisir.

\section{Pengaruh Profitabilitas (ROA) terhadap Kecurangan Pelapor-an Keuangan}

Pernyataan hipotesis ketiga menyatakan bahwa rasio profitabilitas yang diproksoikan dengan Return On Assets (ROA) berpengaruh negatif terhadap kecurangan pelaporan keuangan. Berdasarkan hasil uji regresi logistik dapat ditarik kesimpulan bahwa hipotesis ketiga tidak diterima. Sedangkan dari hasil analisis dapat terlihat bahwa nilai rata-rata dari kecurangan pelaporan keuangan sebesar -0,01 sedangkan rata-rata dari perusahaan yang tidak melakukan kecurangan adalah 0,10 .

Penelitian ini mendukung penelitian Persons (1995) yang mengatakan bahwa profitabilitas tidak berpengaruh terhadap terjadinya kecurangan pelaporan keuangan. Sejalan dengan penelitian Amara (2013) yang mengatakan bahwa kinerja perusahaan yang rendah tidak mempengaruhi terjadinya kecurangan pelaporan keuangan. perusahaan dengan tingkat profitabilitas yang rendah juga andil memberi dorongan bagi manajemen dalam mengungkapkan lebih saji revenue atau kurang saji expenses.

\section{Pengaruh Capital Turnover (CATO) terhadap Kecurangan Pelaporan Keuangan}

Pernyataan hipotesis ke empat menyatakan bahwa capital turnover berpengaruh negatif terhadap kecurangan pelaporan keuangan. Berdasarkan hasil uji regresi logistik dapat ditarik kesimpulan bahwa hipotesis dapat diterima. Hal ini didukung dengan koefisien yang searah dengan tingkat rata-rata 0,46 dan 1,003.

Berdasarkan hasil diatas, dapat disimpulkan bahwa perusahaan yang melakukan kecurangan pelaporan keuangan sebagian besar menunjukkan nilai capital turnover dibawah nilai rata-rata, sehingga dapat disimpulkan bahwa kecurangan pelaporan 
keuangan terjadi pada perusahaan yang nilai capital turnovernya yang rendah atau semakin menurun akan secara efektif meningkatkan kemungkinan terjadinya kecurangan akuntansi pada perusahaan yang listed di Bursa Efek Indonesia.

\section{KESIMPULAN DAN SARAN}

Berdasarkan hasil analisis diatas, maka dapat disimpulkan bahwa likuiditas berpengaruh positif terhadap kecurangan laporan keuangan, leverage berpengaruh positif terhadap kecurangan laporan keuangan dan capital turnover berpengaruh positif terhadap kecurangan laporan keuangan.

\section{REFERENSI}

ACFE. (2002). Fraud Examiners Manual, Third Editin. New York.

AICPA. (1997). "Consideration of Fraud in a Financial Statement Audit". Statement on Auditing Standards No. 82. American Institut of Certified Public Accountants. New York.

Albrecht, W. Steve. (2002). Fraud Examination. Thomson South-Western, USA.

Ashari dan Santoso, PB. (2005). Analisis Statistik dengan Microsoft Exel dan SPSS. Yogyakarta Andi Offset.

Amara, Ines., Amar, Anis. B., dan Jaoboui, Anis. (2013). "Detection of Fraud in Financial Statement: French Companies asS a Case Study". International Journal of Academic Research in Business and Social Sciences. Vol.3; No.5; ISSN: 2222-6990.

Amrizal. (2004). "Pencegahan dan Pendesteksian Kecurangan oleh Auditor Internal". BPKP. Jurmal Anti Korupsi. (Diakses: 31 Januari 2012).

Ansar, Muhammad (2013). "Analisis Faktor-Faktor yang Mempengaruhi Kecurangan Pelaporan Keuangan pada Perusahaan Publik di Indonesia" Tesis UNDIP.

Ardianawati, Wahyu. \& Puspita, Dyah R. (2011). "Demoralisasi Birokrasi: (Fenomena Korupsi dan Red Fleg di Sektor Publik). Journal Magister Ilmu Administrasi Universitas Jenderal Soedirman.

Badan Pengawas Pasar Modal dan Lembaga Keuangan. (2006). Annual Report BapepamLK Tahun 2006. Jakarta

Baridwan, Zaki. (2004). Intermediate Accounting. Yogyakarta: BPFE Yogyakarta.

Beasley, M. (1996). "An Empirical Analysis of the Relation between the Board of Director Composition and Financial Statement Fraud". American Accounting Associ-ation. The Accounting Review. Vol. 71. No. 4. Halaman: 443-465.

Beneish, M. (1999). "The Detection of Earning Manipulation". Accounting Forum. Financial Analysis Journal. PP 24-36.

Che-Ahmad, A., \& Abibin, S. 2008. Audit Delay of Listed Companies : A case of Malaysia. International Business Research, Vol. 1; No. 4; pp: 32-39.

Christie, A. (1990). "Aggregation of Test Statistics: An Evaluation of the Evidence on Contracting and Size Hypotheses," Journal of Accounting and Economics, January 1990.

Cressey, Donald. (1953). "The Internal Auditor as Fraud Buster". Managerial Auditing Journal, MCB Univercity Press, Volume 14, Nomor 7. Hal: 351-362.

Dechow, P., Larson, \& Sloan. (2011). "Predicting Material Accounting Misstatements". Contemporary Accounting Research; Vol. 28; No: 1.

Eisenhardt, Kathleem. M. (1989). Agency Theory: An Assesment and Review. Academy of Management Review, Vol.14, Hal: 57-74.

Fuad. (2005). "Simultanitas dan Trade-Off Pengambilan Keputusan Finansial dalam Mengurangi Konflik Agensi: Peran dari Corporate Ownership". Simposium Nasional Akuntansi VIII, IAI, 2005. 
Gaganis, C. (2009). "Clasification Techniques for the Identification of Falsified Financial Statements: A Comparative Analysis". Inteligent System in Accounting, Finance and Management. Vol. 16; No. 3.

Ghazali, Imam. (2006). Analisis Multivariate Lanjutan dengan Program SPSS (Edisi 1.). Semarang: Badan Penerbit Universitas Diponegoro.

Ghozali, Imam. (2006). Aplikasi Analisis Multivariat dengan Program SPSS (Cetakan IV). Semarang: Badan Penerbit Universitas Diponegoro.

Harahap. (2006). "Pengaruh Pengawasan terhadap Efisiensi Kerja pada PT. Sunindo Varia Motor Gemilang Medan". Jurnal Fakultas Ekonomi USU.

Harahap, Sofyan Syafri. (2009). "Analisis Kritis Atas Laporan Keuangan”. Jakarta: Raja Grafindo Persada.

Huang, Hua-Wei, dan Sheela Thiruvadi. (2010). "Audit Committee Characteristics and Corporate Fraud. International Journal of Public Information System. Halaman 71-82.

Ikatan Akuntan Indonesia, (2001). Standar Profesional Akuntan Publik. Jakarta: Salemba Empat

Indriyanto, N. d. (2002). Metodologi Penelitian Bisnis untuk Akuntansi dan Manajemen. Yogyakarta: BPFE Yogyakarta.

Jensen, Michael \& Meckling, William H. (1976). "Theory of the Firm: Managerial Behavior, Agency Cost and Ownership Structure". Journal of Financial Economics, Volume 3.

Jogiyanto. (2004). Metodologi Penelitian Bisnis, Yogyakarta, BPFE.

Munawir. (2010). “Analisis Laporan Keuangan”. Edisi 4, Liberty, Yogyakarta.

Muntoro. (2011). "Alat Pemantau Manajemen Laba dalam Laporan Keuangan Perusahaan". Artikel Majalah Kredibilitas Akuntansi. Hal 65-70.

Persons, D. Obeua. (1995). "Using Financial Statement Data to Identify Factors Associated with Fraudulent Financial Reporting". Journal of Applied Business Research, Vol.11, Hal: 38-46.

Prabandari, Jeane Deart M. Dan Rustiana. (2007). "Beberapa Faktor yang Berdampak pada Audit Delay (Studi Empiris pada Perusahaan-perusahaan yang Terdaftr di BEJ). Universitas Atmajaya. Vol. 11; No. 1; PP 27-39.

Prajanto, Agung. (2012). Pengaruh Rasio Keuangan dan Budaya Perusahaan terhadap Kecurangan Pelaporan Keuangan (Studi empiris pada perusahaan yang terdaftar di Bursa Efek Indonesia tahun 2006-2010). Tesis UNDIP.

Prasetyo, Andrian Budi. (2012). "Pengaruh Karakteristik Komite Audit dan Perusaahaan terjadap Kecurangan Pelaporan keuangan (Studi Empiris pada Perusahaan yang Listed di Bursa Efek Indonesia Periode 2006-2010). Tesis UNDIP.

Sekaran, Uma. (2006). Metodologi Penelitian Untuk Bisnis (Edisi 4). Jakarta: Salemba Empat.

Sekaran, Uma. (2000). Research Methods for Business, A Akill-Building Approach. America: Thirt Edition: John Wiley and Sons.

Spathis, Charalambos. T. (2002). "Detection False Financial Statements Using Published Data: Some Evidence from Greece". Managerial Auditing Journal , Halaman: 179-191.

Sunarto. 2009. "Teori Keagenan dan Manajemen Laba". Kajian Akuntansi. Fakultas Ekonomi Unisbank Semarang. Volume 1, Nomor. 1, Halaman: 13-28. ISSN: 19794886.

Wilopo. (2006). "Analisis Faktor-faktor yang Mempengaruhi Kecenderungan Kecurangan Akuntansi: Studi pada Perusahaan Publik dan Badan Usaha Milik Negara di Indonesia". Jurnal Simposium Nasional Akuntansi 9 Padang. STIE Perbanas-Suaraya.

Wuerges, Arthur Filipe Ewald \& Borba Jose A.; (2010). "Accounting Fraud Detection: Is It Possible To Quantify Undiscovered Cases?" Social Science Research Network. http://ssrn.com.abstract=1718652 pp: 1-24.

Zulbay, Agus. 2013. "Manipulasi Laporan Keuangan PT Kereta Api Indonesia". Makalah Etika Bisnis. 14 Mei. 